\title{
Acute type I aortic dissection with or without antegrade stent delivery: Mid-term outcomes
}

Ourania Preventza, MD, ${ }^{\mathrm{a}, \mathrm{b}}$ Jacqueline K. Olive, BA, ${ }^{\mathrm{a}}$ Jane L. Liao, BS, ${ }^{\text {a }}$ Vicente Orozco-Sevilla, MD,,${ }^{\mathrm{a}, \mathrm{b}}$ Katherine Simpson, MS, ${ }^{\mathrm{a}}$ Meredith R. Rodriguez, PhD, ${ }^{\mathrm{a}, \mathrm{c}}$ Matt D. Price, MS, ${ }^{\mathrm{a}, \mathrm{c}}$ Benjamin Y. Cheong, MD, ${ }^{\mathrm{b}}$ Subhasis Chatterjee, MD, ${ }^{a}$ Kim I. de la Cruz, MD, ${ }^{\mathrm{a}, \mathrm{b}}$ Hiruni S. Amarasekara, MS,,${ }^{\mathrm{a}, \mathrm{c}}$ Scott A. LeMaire, MD, ${ }^{a, b, c}$ and Joseph S. Coselli, MD ${ }^{a, b}$

\section{ABSTRACT}

Objective: We determined the effect of antegrade stent delivery in the descending thoracic aorta on short- and mid-term clinical and imaging outcomes for patients who underwent repair of acute DeBakey type I aortic dissection.

Methods: Outcomes were evaluated for 178 patients who underwent acute type I aortic dissection between 2005 and 2016 (standard repair, $\mathrm{n}=115$ [64.6\%]; antegrade stent delivery, $\mathrm{n}=63[35.4 \%]$ ). Propensity score match and multivariable analyses were performed to assess outcomes.

Results: The stent and standard repair groups had similar rates of operative mortality (30-day or in-hospital) $(12.7 \%$ vs $17.4 \%, P=.41)$, persistent stroke $(6.3 \%$ vs $5.3 \%, P=.75)$, and persistent paraplegia/paraparesis $(1.6 \%$ vs $0.9 \%$, $P=1.0$ ). Propensity score match analysis indicated that the operative mortality rate was higher in the standard repair group $(P=.059)$, which the multivariable analysis confirmed. The persistent stroke rate was nonsignificantly higher in the stent group $(P=.66)$. Persistent paraplegia/paraparesis rates were similar in both groups $(P=1.0)$, and the overall rates of spinal cord ischemia were nonsignificantly higher in the stent group $(P=.18)$. During follow-up (mean duration, $4.6 \pm 3.6 \mathrm{y}$ ), computed tomography showed that stented patients more often had remodeling of the descending thoracic aorta $(P=.0002)$ and somewhat more often had remodeling of the thoracoabdominal aorta $(P=.13)$. Stented patients also had fewer subsequent procedures $(P=.25)$. The 3 - and 5-year survivals were $73.3 \% \pm 6.9 \%$ and $49.9 \% \pm 7.6 \%$ in the matched stented group and $66.3 \% \pm 9.4 \%$ and $41.6 \% \pm 7.7 \%$ in the matched standard group, respectively $(P=.015$ for overall survival).

Conclusions: In the short term, antegrade stent delivery was associated with less operative mortality. In the mid-term, promising remodeling of the false lumen was seen in stented patients, as were (nonsignificantly) lower rates of subsequent procedures in the thoracoabdominal aorta. Mid-term survival was also greater in the stented patients. (J Thorac Cardiovasc Surg 2019;158:1273-81)

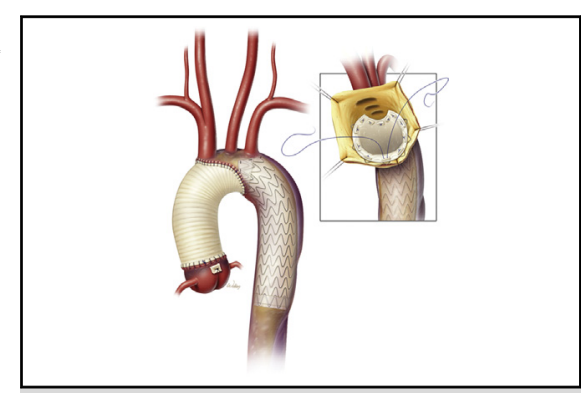

The stent graft is incorporated into the distal suture line along the lesser curvature.

\section{Central Message}

Antegrade stenting during surgery for acute type I aortic dissection may reduce operative mortality, promote remodeling, and improve survival. Results are inconclusive for spinal cord ischemia.

\section{Perspective}

Despite advancements in cardiac surgery, type I aortic dissection remains a challenging problem. Imaging data are useful as we try to determine the ideal extent of the initial operation in affected patients. Antegrade stent delivery during the initial repair, although promising, has not yet proven to eliminate downstream operations in the thoracoabdominal aorta. More studies are needed.

See Commentaries on pages 1282 and 1283.

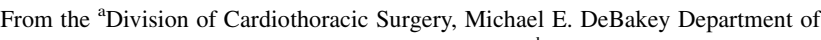
Surgery, Baylor College of Medicine, Houston, Tex; 'bepartment of Cardiovascular Surgery, Texas Heart Institute, Houston, Tex; and ${ }^{\mathrm{c} S u r g i c a l}$ Research Core, Michael E. DeBakey Department of Surgery, Houston, Tex.

Received for publication April 26, 2018; revisions received Sept 28, 2018; accepted for publication Nov 30, 2018; available ahead of print April 5, 2019.

Address for reprints: Ourania Preventza, MD, Division of Cardiothoracic Surgery, Michael E. DeBakey Department of Surgery, Baylor College of Medicine, BCM 390, One Baylor Plaza, Houston, TX 77030 (E-mail: preventz@ bcm.edu). $0022-5223 / \$ 36.00$

Copyright (c) 2019 by The American Association for Thoracic Surgery https://doi.org/10.1016/j.jtcvs.2018.11.145
}

Despite advancements in cardiac surgery, acute proximal ascending aortic dissection (DeBakey type I or Stanford type A aortic dissection) continues to be a challenging problem associated with significant mortality and morbidity, as shown in large registries and at specialized centers. ${ }^{1-9}$ During surgical treatment of acute type A or type I aortic dissection, the main goals are to keep the patient alive and prevent subsequent operations in the proximal aorta and in the descending and thoracoabdominal aorta. 


\section{Abbreviations and Acronyms}

$\mathrm{CAD}=$ coronary artery disease

$\mathrm{CT}=$ computed tomography

Although initial resection of all dissected aortic tissue decreases the risk of late adverse aortic events, it does not completely eliminate the need for subsequent surgery. ${ }^{9}$ To decrease the need for future operations in the thoracoabdominal aorta, some have advocated more aggressive initial resection, with total arch replacement, stent delivery, or both in the descending thoracic aorta. ${ }^{10-13}$ Early clinical and imaging results of stent delivery in the descending thoracic aorta appear promising in that they show distal aortic remodeling and possible resolution of malperfusion, ${ }^{11-13}$ but mid-term results are limited. ${ }^{14}$

To address this gap in the available data, we reviewed the mid-term outcomes of patients who underwent hemiarch or total arch replacement (ie, standard surgical repair) for acute type I aortic dissection. We compared these patients' outcomes with those of patients who underwent an additional concomitant antegrade stent delivery during the surgical repair of their proximal dissection.

\section{PATIENTS AND METHODS}

Over a 12-year period (2005-2016), 178 consecutive patients underwent emergency repair of acute type I aortic dissection. Patients with acute type II aortic dissection were excluded. Most of the patients were transferred to our institution from an outside facility. A total of 115 patients had the traditional standard repair with hemiarch $(\mathrm{n}=102,88.7 \%)$ or total arch replacement $(\mathrm{n}=13,11.3 \%)$, and 63 patients had the standard repair plus antegrade stent delivery in the descending thoracic aorta (hemiarch, $\mathrm{n}=60,95.2 \%$; total arch, $\mathrm{n}=3,4.8 \%$ ). We started adding the stent in the descending thoracic aorta during the first few months of 2009; before then, all patients had the standard repair. Initially, we used the stented approach in patients with malperfusion; then we expanded our indications to patients with arch tears or a dilated proximal descending thoracic aorta. Among patients with a genetic connective tissue disorder, we used the stent approach only in those who presented with malperfusion.

The data were obtained from our prospectively maintained database. All patients' hospital records and operative diagrams were reviewed to obtain preoperative and intraoperative data (Table 1). The follow-up was active; follow-up data were obtained with telephone calls, clinic visits, and communication with patients' primary doctors or cardiologists.

TABLE 1. Preoperative and intraoperative characteristics

\begin{tabular}{|c|c|c|c|c|c|c|c|c|}
\hline \multirow[b]{2}{*}{ Characteristic } & \multicolumn{4}{|c|}{ Unmatched patients } & \multicolumn{4}{|c|}{ Propensity-matched patients* } \\
\hline & $\begin{array}{c}\text { Overall } \\
(\mathbf{N}=\mathbf{1 7 8})\end{array}$ & $\begin{array}{c}\text { Stent } \\
(\mathrm{n}=63)\end{array}$ & $\begin{array}{l}\text { Standard } \\
\text { treatment } \\
(n=115)\end{array}$ & $P$ value & $\begin{array}{l}\text { Overall } \\
(n=92)\end{array}$ & $\begin{array}{c}\text { Stent } \\
(n=46)\end{array}$ & $\begin{array}{c}\text { Standard } \\
\text { treatment } \\
(n=46)\end{array}$ & Std diff \\
\hline \multicolumn{9}{|l|}{ Preoperative } \\
\hline Age at admission, $y$ & $57.9 \pm 14.3$ & $62.0 \pm 13.1$ & $55.7 \pm 14.5$ & .0039 & $60.4 \pm 12.7$ & $60.4 \pm 13.1$ & $60.3 \pm 12.5$ & 0.01 \\
\hline Male gender & $122(68.5)$ & $44(69.8)$ & $78(67.8)$ & .78 & $67(72.8)$ & $32(69.6)$ & $35(76.1)$ & -0.15 \\
\hline Genetic disorder & $63(35.4)$ & $12(19.1)$ & $51(44.4)$ & .0007 & $20(21.7)$ & $10(21.7)$ & $10(21.7)$ & 0.00 \\
\hline Diabetes & $21(11.8)$ & $7(11.1)$ & $14(12.2)$ & .83 & $13(14.1)$ & $6(13.0)$ & $7(15.2)$ & -0.06 \\
\hline Tobacco use & $89(50.0)$ & $36(57.1)$ & $53(46.1)$ & .16 & $51(55.4)$ & $26(56.5)$ & $25(54.4)$ & 0.04 \\
\hline History of CVD $\dagger$ & $18(10.1)$ & $6(9.5)$ & $12(10.4)$ & .85 & $11(12.0)$ & $5(10.9)$ & $6(13.0)$ & -0.07 \\
\hline Stroke & $12(6.7)$ & $4(6.4)$ & $8(7.0)$ & 1.00 & $7(7.6)$ & $4(8.7)$ & $3(6.5)$ & 0.08 \\
\hline History of $\mathrm{CAD}_{\ddagger}^{\ddagger}$ & $45(25.3)$ & $20(31.8)$ & $25(21.7)$ & .14 & $25(27.2)$ & $14(30.4)$ & $11(23.9)$ & 0.15 \\
\hline CABG & $11(6.2)$ & $5(7.9)$ & $6(5.2)$ & .52 & $9(9.8)$ & $4(8.7)$ & $5(10.9)$ & -0.07 \\
\hline Renal dysfunction & $45(25.3)$ & $12(19.1)$ & $33(28.7)$ & .16 & $20(21.7)$ & $9(19.6)$ & $11(23.9)$ & -0.11 \\
\hline Malperfusion & $59(33.3)$ & $34(54.8)$ & $25(21.7)$ & $<.0001$ & $37(40.2)$ & $18(39.1)$ & $19(41.3)$ & -0.04 \\
\hline Intubation on arrival & $16(9.0)$ & $7(11.3)$ & $9(7.8)$ & .44 & $13(14.1)$ & $6(13.0)$ & $7(15.2)$ & -0.06 \\
\hline \multicolumn{9}{|l|}{ Intraoperative } \\
\hline Hemiarch (vs TAR) & $162(91.0)$ & $60(95.2)$ & $102(88.7)$ & .14 & $83(90.2)$ & $44(95.7)$ & $39(84.8)$ & 0.37 \\
\hline Bilateral ACP delivery & $101(56.7)$ & $54(85.7)$ & $47(40.9)$ & $<.0001$ & $61(66.3)$ & $40(87.0)$ & $21(45.7)$ & 0.97 \\
\hline \multicolumn{9}{|l|}{ Concomitant procedure } \\
\hline Any root procedure & $29(16.3)$ & $7(11.1)$ & $22(19.1)$ & .17 & $10(10.9)$ & $5(10.9)$ & $5(10.9)$ & 0.00 \\
\hline AV repair & $121(68.0)$ & $48(76.2)$ & $73(63.5)$ & .082 & $64(69.6)$ & $33(71.7)$ & $31(67.4)$ & 0.09 \\
\hline CABG & $11(6.2)$ & $4(6.4)$ & $7(6.1)$ & 1.00 & $6(6.5)$ & $3(6.5)$ & $3(6.5)$ & 0.00 \\
\hline \multicolumn{9}{|c|}{ Intraoperative times (min) } \\
\hline HCA & $41.6 \pm 20.6$ & $45.2 \pm 17.5$ & $39.6 \pm 21.9$ & .0034 & $43.9 \pm 23.9$ & $44.4 \pm 17.4$ & $43.5 \pm 29.2$ & 0.04 \\
\hline $\mathrm{CPB}$ & $138.0 \pm 70.1$ & $128.4 \pm 52.1$ & $143.3 \pm 77.9$ & .45 & $137.3 \pm 66.7$ & $127.6 \pm 45.9$ & $146.9 \pm 81.9$ & -0.29 \\
\hline $\mathrm{ACP}$ & $37.7 \pm 18.9$ & $41.7 \pm 16.8$ & $35.5 \pm 19.7$ & .0022 & $39.6 \pm 19.7$ & $40.8 \pm 16.3$ & $38.3 \pm 22.8$ & 0.13 \\
\hline Cardiac ischemia & $103.4 \pm 58.5$ & $101.6 \pm 36.0$ & $104.3 \pm 67.9$ & .32 & $100.4 \pm 41.3$ & $100.7 \pm 34.0$ & $100.1 \pm 47.9$ & 0.02 \\
\hline
\end{tabular}

Data are presented as number (\%) or as mean $\pm \mathrm{SD}$. Std diff, Standardized difference; $C V D$, cardiovascular disease; $C A D$, coronary artery disease; $C A B G$, coronary artery bypass grafting; $T A R$, total arch replacement; $A C P$, antegrade cerebral perfusion; $A V$, aortic valve; $H C A$, hypothermic circulatory arrest; $C P B$, cardiopulmonary bypass. *Propensity matching was based only on preoperative characteristics. †Cerebrovascular disease: history of transient ischemic attack, stroke, carotid endarterectomy, or cerebral aneurysm. $\ddagger$ CAD: history of angina, myocardial infarction, coronary artery bypass grafting, percutaneous transluminal coronary angioplasty and stenting, or 1-, 2-, or 3-vessel CAD. 
Institutional review board approval was obtained from the Baylor College of Medicine, and informed consent or waiver of consent for data collection was obtained from all patients. Our definitions of preoperative variables, intraoperative ischemic and circulatory arrest times, and outcomes have been described previously. ${ }^{11}$

Available computed tomography (CT) follow-up data were reviewed by 2 surgeons (O.P. and J.S.C.); any discrepancies were resolved by a cardiovascular radiologist (B.Y.C.). Data recorded were based on the latest available CT scan. The CT angiograms were interpreted as follows: The false lumen was considered patent if there was no evidence of thrombus formation along the entire length of the thoracoabdominal aorta. The false lumen was considered partially thrombosed if there was evidence of incomplete thrombus formation in the thoracoabdominal aorta, and the false lumen was considered completely thrombosed if no contrast material was visible within it. In patients with stents, we specified the patency of the false lumen in relationship to the stent: If the false lumen was thrombosed only at the level of the stent and was otherwise patent, then the entire thoracoabdominal aorta was considered partially thrombosed. If the false lumen was partially thrombosed at the area of the stent and the remaining thoracoabdominal aorta was fully patent or partially thrombosed, then the thoracoabdominal aorta was considered partially thrombosed. If no thrombus formation was seen at the area of the stent or in the remaining thoracoabdominal aorta, then we considered it patent. When the entire descending thoracic aorta or the thoracoabdominal aorta was thrombosed, we considered it remodeled. Data were also collected regarding secondary open or endovascular procedures in the descending thoracic and thoracoabdominal aorta.

\section{Standard Surgical Technique}

We have previously outlined in detail our standard surgical technique. ${ }^{6}$ We use echocardiography and near-infrared spectroscopy in all cases. Our first choice of site for the arterial inflow cannula in these cases is the innominate artery; we cannulate the right axillary artery if the innominate artery is dissected and the femoral artery in patients in extremis. ${ }^{7}$ Central cannulation, as we have previously described in elective procedures, ${ }^{15}$ is used solely in cases in which malperfusion is encountered after cardiopulmonary bypass is initiated. Cannulation via the left ventricular apex is another option for patients in extremis. We induce moderate hypothermia, cooling patients to an approximate nasopharyngeal temperature of $24^{\circ} \mathrm{C}$. We use a left ventricular sump to avoid left ventricular distension, and we do not apply an aortic crossclamp during cooling except in the rare circumstance in which the heart becomes distended because of massive aortic regurgitation despite the left ventricular vent.

Our distal repair involves resecting all dissected tissue, approximating the false and true lumens, and replacing the proximal arch (hemiarch) unless the arch is dilated more than $5 \mathrm{~cm}$ or has a tear that cannot be repaired primarily, in which case we replace the full arch. During the rewarming period, the other necessary procedures are performed on the aortic valve (resuspension, commissuroplasty, replacement) or the aortic root (repair or replacement).

\section{Concomitant Stent in the Descending Thoracic Aorta}

We have previously described an early version of our technique involving concomitant stent delivery in the descending thoracic aorta. ${ }^{11}$ In the current series, all stent delivery was performed antegrade. The stent of choice was the GORE TAG graft (WL Gore \& Associates, Inc, Flagstaff, Ariz) before October 2011 and the Conformable TAG device (WL Gore \& Associates) thereafter except in 2 cases; we used a Medtronic valiant stent (Medtronic Vascular, Santa Rosa, Calif) in 1 patient and a Cook Zenith stent (Cook Medical, Bloomington, Ind) in the other. If the patient's anatomy was favorable, part of the proximal portion of the stent graft was incorporated into the distal suture line along the lesser curvature of the arch at the level of the left subclavian artery (Figure 1). Occasionally, the patient's anatomy did not permit this and the left subclavian artery was too distal, so we used one or two 3-0 Prolene sutures in the lesser curvature of the arch to anchor the stent graft. During the study period, we noticed at follow-up that the area around the left subclavian artery was a source of endoleak in these patients, and as a result we started using circumferential 3-0 Prolene sutures to anchor the graft in the distal arch and proximal descending thoracic aorta. The size of the stent graft was $10 \%$ to $15 \%$ larger than the long axis of the true lumen of the proximal descending thoracic aorta, and the length was 10 to $20 \mathrm{~cm}$, depending on the height and body habitus of the patient. The stent graft was delivered under direct vision over a stiff Amplatz wire, which was not advanced more than 15 to $20 \mathrm{~cm}$ distally. Warm water was applied at the end of the stent deployment for full stent graft expansion because the deployment was performed during the hypothermic circulatory arrest period. Although it is our preference to place the wire antegrade under direct vision to direct the stent, an alternative solution is to insert the soft wire and catheter retrograde via the femoral vessels at the beginning of the operation.

\section{Follow-up}

Twenty-eight patients died in the hospital or within 30 days; 2 of these deaths were intraoperative. For the entire cohort (including the patients who died intraoperatively), the mean follow-up period was $3.8 \pm 3.7$ years. For survivors $(n=150)$, the mean follow-up period after intervention was $4.6 \pm 3.6$ years. A total of 121 patients had at least $1 \mathrm{CT}$ imaging study after intervention, and 96 of these had at least 1 additional CT study during the follow-up period. The median (interquartile range) time from discharge to most recent imaging study was $3.4(0.7-5.3)$ years for the full cohort, $2.6(0.7-3.8)$ years for the patients with stents, and 3.9 (1.1-6.4) years for the standard repair group.

\section{Statistical Analysis}

Statistical analyses were performed with SAS Version 9.4 (SAS Institute Inc, Cary, NC). All tests were 2 -sided. $P$ values were not adjusted for multiplicity. Differences in the distribution of preoperative and intraoperative characteristics were tested with chi-square analysis or the Fisher exact test for the categoric variables and with the Wilcoxon 2-sample test for the continuous variables.

To minimize the preoperative differences between the stent and standard repair groups, a propensity score match analysis was done, based only on preoperative characteristics, using a 1:1 greedy match algorithm without replacement. A Love plot-a graphical representation of standardized differences of the preoperative variables between the unmatched and matched cohorts-was also included (Figure 2). Stenting versus standard repair was the dependent variable in the logistic regression model used to compute the propensity scores, and the following 10 preoperative variables were included: age, gender, genetic disorder, diabetes, tobacco use, cerebrovascular disease composite (ie, history of transient ischemic attack, stroke, carotid endarterectomy, or cerebral aneurysm), coronary artery disease [CAD] composite (ie, history of angina, myocardial infarction, coronary artery bypass grafting, percutaneous transluminal coronary angioplasty and stenting, or 1-, 2-, or 3-vessel CAD), intubation on arrival, renal dysfunction, and malperfusion.

The matching process yielded 46 matched pairs. To determine whether the preoperative risk factors were well balanced, we calculated standardized differences to compare the preoperative characteristics of the unmatched and matched groups. All of the standardized differences were less than $10 \%$ except for male gender, composite CAD, and renal dysfunction, for which the standardized differences were slightly higher than $10 \%$ : $-0.15,0.15$, and, -0.11 , respectively. When outcomes were compared between the propensity-matched patients, conditional logistic regression was used to calculate the $P$ values, odds ratios, and $95 \%$ confidence intervals (CIs). No further adjustment was needed because the potential confounding factors were bundled by the propensity score match. 


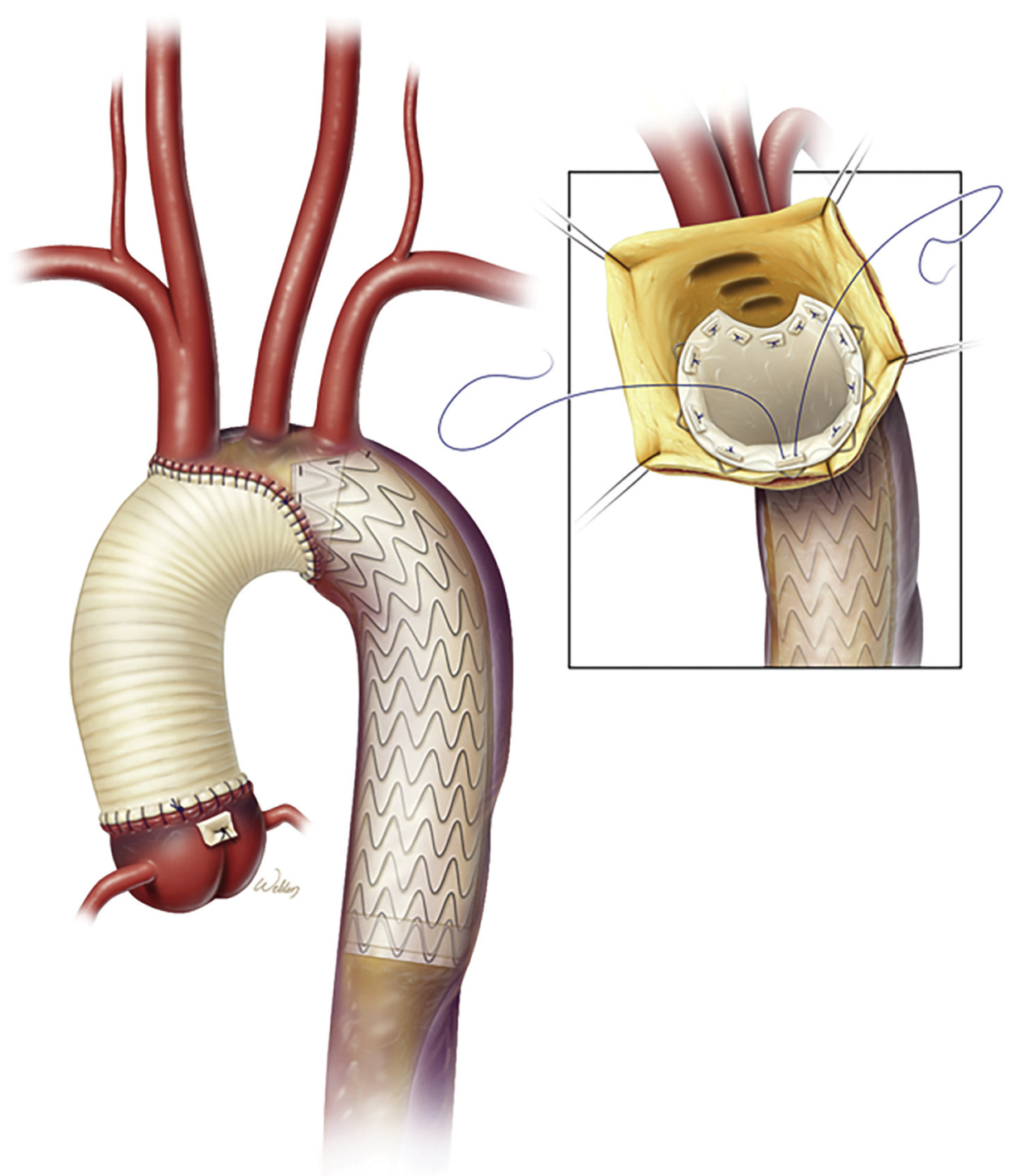

FIGURE 1. Stent graft is incorporated into the distal suture line along the lesser curvature of the arch.

To identify potential predictors of adverse postoperative outcomes, multivariable analyses were conducted. We ran logistic regressions to model the adverse outcomes with stepwise selection with data from all patients $(\mathrm{N}=178)$ by using the following preoperative and intraoperative variables: stent, surgery year, age, gender, genetic disorder, diabetes, hypertension, tobacco use, cerebrovascular disease composite, CAD composite, pulmonary disease composite, renal dysfunction, malperfusion, intubation on arrival, hemiarch repair, bilateral antegrade cerebral perfusion delivery, any concomitant aortic root procedure, aortic valve repair, aortic valve replacement, concomitant coronary artery bypass grafting, hypothermic circulatory arrest time, cardiac ischemic time, and lowest temperature during circulatory arrest. Inspecting the variance inflation factors verified that multicollinearity was not an issue. Kaplan-Meier analysis was performed (IBM SPSS statistics version 24, New York, NY) to create survival curves for the propensity-matched data broken out by the stent and standard repair groups. The log-rank test was used to test for differences in survival.

\section{RESULTS}

Short-term outcomes in the unmatched and propensitymatched patients are shown in Table 2. Propensity score match analysis and multivariable analysis showed similar results with regard to in-hospital and operative mortality. The rate of in-hospital mortality was higher in the standard repair group than in the stent group in both matched $(P=.059)$ and unmatched $(P=.41)$ comparisons (Table 2). In addition, in the multivariable analysis, the hybrid approach with stent delivery appeared to be protective against operative mortality (Table 3 ). Preoperative malperfusion and whether patients were intubated on arrival were also predictors of operative mortality (Table 3). The persistent stroke rates were similar between the stent and 


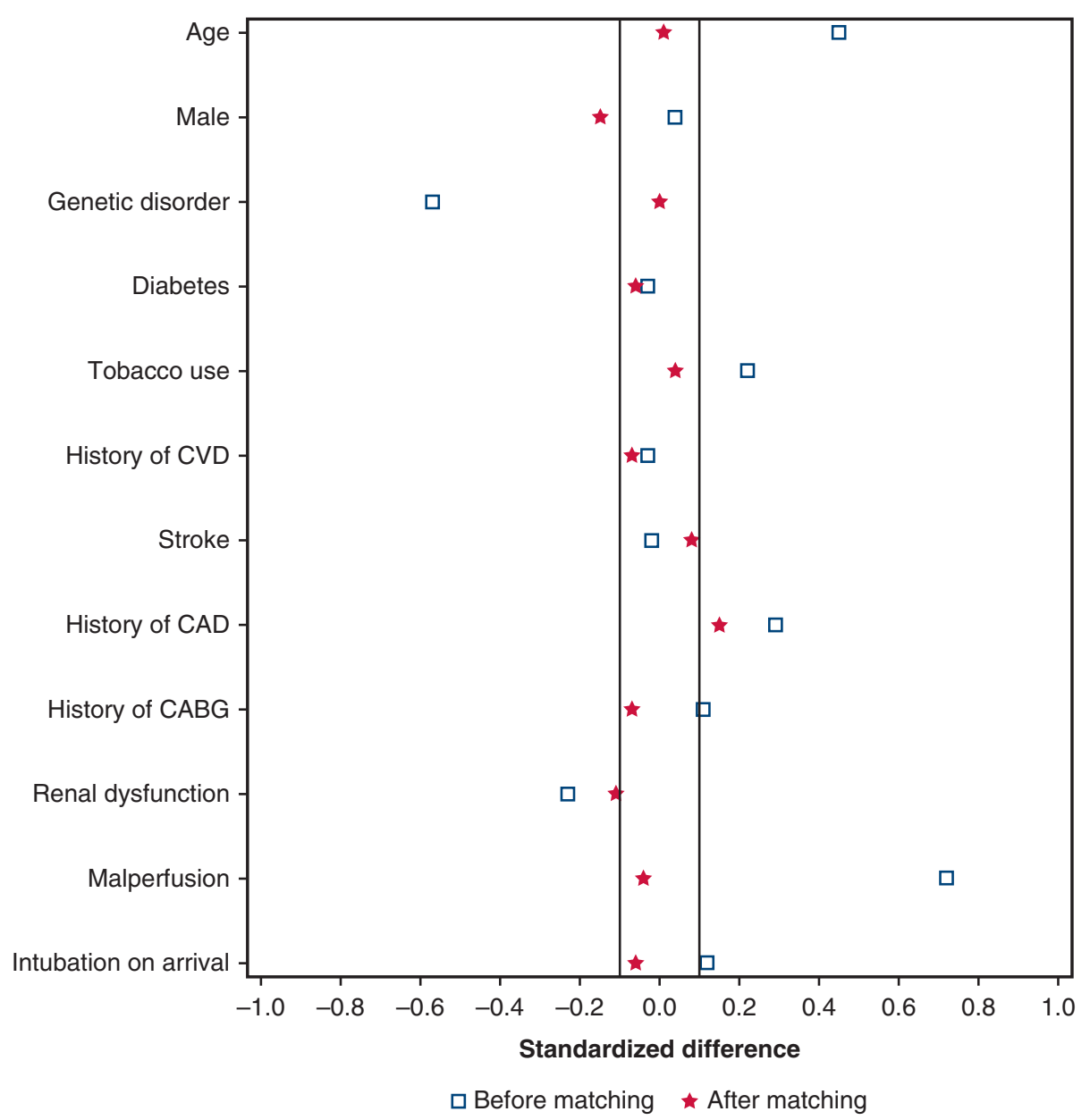

FIGURE 2. Love plot—a graphical representation of standardized differences between the unmatched and matched cohorts. $C V D$, Cardiovascular disease; $C A D$, coronary artery disease; $C A B G$, coronary artery bypass grafting.

standard repair groups: $6.3 \%$ versus $5.3 \%(P=.75)$ in the unmatched group and $6.5 \%$ versus $4.6 \%(P=.66)$ in the matched group.

Other findings also held true for both the matched and the unmatched patients. Overall spinal cord ischemia rates were higher for the stent patients, but not significantly so, and the results are based on small numbers. The rate of persistent spinal cord ischemia was the same in both groups (these patients had hemiarch repair, and 1 was stented). The rate of transient spinal cord ischemia was higher in the stent group. Adding the effect of stent length to the analysis did not provide any additional insight. No predictors of spinal cord ischemia were found in the multivariable analysis.

In a subgroup analysis of the entire cohort (unmatched patients) that included only patients with hemiarch repair with or without stent delivery (ie, we excluded the total arch patients), operative mortality continued to be higher in the standard repair group than in the stented hemiarch group ( $16.7 \%$ vs $11.7 \%, P=.39)$, and HCA time continued to be longer in the stented hemiarch group
$(42.6 \pm 13.2 \mathrm{~min})$ than in the standard repair group (36.6 \pm 18.9 minutes; $P=.0006$ ). In the overall cohort, when all patients who underwent total arch repair $(\mathrm{n}=16)$ were compared with all patients who underwent hemiarch repair $(n=162)$, the total arch patients had nonsignificantly higher rates of mortality $(25.0 \%$ vs $14.8 \%, P=.29)$ and stroke $(25.0 \%$ vs $9.3 \%, P=.074)$.

\section{Fate of the False Lumen and Secondary Aortic Procedures}

A higher percentage of the standard repair group had secondary aortic procedures, but the difference was not statistically significant $(P=.25)$ (Table 4$)$. With regard to the fate of the false lumen, $63.5 \%$ of patients $(\mathrm{n}=33)$ who had a stent placed in the descending thoracic aorta had complete thrombosis of the stented area, whereas only $29 \%$ $(n=20)$ of the patients who underwent the traditional repair had remodeling of the descending thoracic aorta $(P=.0002)$. Only 1 patient from each of these 2 groups required a subsequent endovascular procedure. With regard 
TABLE 2. Outcomes

\begin{tabular}{|c|c|c|c|c|c|c|c|c|c|}
\hline \multirow[b]{2}{*}{ Outcomes } & \multicolumn{4}{|c|}{ Unmatched patients } & \multicolumn{4}{|c|}{ Propensity-matched patients } & \multirow[b]{2}{*}{$\begin{array}{l}\text { Odds ratio } \\
(95 \% \mathrm{CI})\end{array}$} \\
\hline & $\begin{array}{c}\text { Overall } \\
(\mathbf{N}=\mathbf{1 7 8})\end{array}$ & $\begin{array}{c}\text { Stent } \\
(\mathrm{n}=63)\end{array}$ & $\begin{array}{l}\text { Standard } \\
\text { treatment } \\
(\mathrm{n}=115)\end{array}$ & $\begin{array}{c}P \\
\text { value }\end{array}$ & $\begin{array}{l}\text { Overall } \\
(\mathbf{n}=92)\end{array}$ & $\begin{array}{c}\text { Stent } \\
(n=46)\end{array}$ & $\begin{array}{c}\text { Standard } \\
\text { treatment } \\
(n=46)\end{array}$ & $\begin{array}{c}P \\
\text { value }\end{array}$ & \\
\hline $\begin{array}{l}\text { Operative mortality (30-d or } \\
\text { in-hospital) }\end{array}$ & $28(15.7)$ & $8(12.7)$ & $20(17.4)$ & .41 & $20(21.7)$ & $6(13.0)$ & $14(30.4)$ & .059 & $0.39(0.14-1.08)$ \\
\hline 30-d mortality & $25(14.0)$ & $8(12.7)$ & $17(14.8)$ & .70 & 18 (19.6) & $6(13.0)$ & $12(26.1)$ & .16 & $0.50(0.19-1.33)$ \\
\hline Persistent stroke & $10(5.7)$ & $4(6.3)$ & $6(5.3)$ & .75 & $5(5.6)$ & $3(6.5)$ & $2(4.6)$ & .66 & $1.50(0.25-8.98)$ \\
\hline Transient stroke & $9(5.1)$ & $4(6.3)$ & $5(4.4)$ & .72 & $3(3.3)$ & $2(4.4)$ & $1(2.3)$ & .57 & $2.00(0.18-22.06)$ \\
\hline Spinal cord ischemia* & $7(4.0)$ & $5(7.9)$ & $2(1.8)$ & .099 & $5(5.6)$ & $4(8.7)$ & $1(2.3)$ & .18 & $4.00(0.45-35.79)$ \\
\hline Persistent & $2(1.1)$ & $1(1.6)$ & $1(0.9)$ & 1.00 & $2(2.2)$ & $1(2.2)$ & $1(2.3)$ & 1.00 & $1.00(0.063-15.99)$ \\
\hline Transient & $5(2.8)$ & $4(6.4)$ & $1(0.9)$ & .056 & $3(3.3)$ & $3(6.5)$ & $0(0.0)$ & .083 & $3.85(0.58-\infty)$ \\
\hline Resolved malperfusion $\dagger$ & $44 / 58(75.9)$ & $25 / 34(73.5)$ & $19 / 24(79.2)$ & .62 & $24 / 36(66.7)$ & $11 / 18(61.1)$ & $13 / 18(72.2)$ & 1.00 & $1.00(0.20-4.96)$ \\
\hline Respiratory failure & $86(48.9)$ & $33(52.4)$ & $53(46.9)$ & .49 & $42(46.7)$ & $23(50.0)$ & $19(43.2)$ & .38 & $1.00(0.61-3.67)$ \\
\hline Postoperative renal dysfunction & $42(23.9)$ & $16(25.4)$ & $26(23.0)$ & .72 & $25(27.8)$ & $12(26.1)$ & $13(29.6)$ & .81 & $0.89(0.34-2.30)$ \\
\hline Persistent dialysis dependence & $16(9.1)$ & $5(7.9)$ & $11(9.7)$ & .69 & $12(13.3)$ & $5(10.9)$ & $7(15.9)$ & .57 & $0.71(0.23-2.25)$ \\
\hline Reoperation for bleeding & $14(8.0)$ & $8(12.7)$ & $6(5.3)$ & .082 & $10(11.1)$ & $6(13.0)$ & $4(9.1)$ & .53 & $1.50(0.42-5.32)$ \\
\hline
\end{tabular}

Data are presented as number (\%). CI, Confidence interval. *Spinal cord ischemia: persistent or transient paraparesis or paraplegia. $\dagger$ Denominators represent the total number of patients with malperfusion in each group.

to the entire thoracoabdominal aorta, the rate of patency of the false lumen in the entire aneurysm was similar in the stented $(69.2 \%)$ and standard repair groups $(75.4 \%$; $P=.45)$, and $20.5 \%(\mathrm{n}=18)$ of all patients had a secondary thoracoabdominal aortic procedure (not a descending thoracic aortic procedure) (4 stented patients [11.1\%], 14 standard repair patients $[26.9 \%], P=.071)$.

Analysis of Kaplan-Meier survival curves for the matched patients revealed that mid-term survival was significantly better in the stent group than in the standard repair group $(P=.015)$ (Figure 3 ).

\section{DISCUSSION}

Debate exists regarding how aggressive and extensive proximal repair should be in patients with acute DeBakey Type I aortic dissection. Selected centers perform extensive repairs with acceptable morbidity and mortality rates. ${ }^{16}$ The primary focus in treating this deadly disease is promoting

TABLE 3. Multivariable analysis

\begin{tabular}{llcc}
\hline \multicolumn{1}{c}{ Outcome } & Predictor variables & P value & Odds ratio (95\% CI) \\
\hline Operative mortality (30-d or in-hospital) & Stent placement & .012 & $0.22(0.066-0.72)$ \\
& CAD composite & .0050 & $4.87(1.61-14.74)$ \\
& Malperfusion & .0028 & $5.57(1.81-17.17)$ \\
& Intubation on arrival & .0006 & $10.12(2.70-37.91)$ \\
& HCA time (min) & .0026 & $1.03(1.01-1.06)$ \\
Stroke & Hemiarch (vs TAR) & .039 & $0.26(0.073-0.93)$ \\
SCI & No predictors & NA & NA \\
SCI (stent only) & No predictors & NA & NA \\
Malperfusion resolved & Intubation on arrival & .0094 & $0.15(0.036-0.63)$ \\
Respiratory failure & Renal dysfunction & .0023 & $3.16(1.51-6.62)$ \\
Postoperative renal dysfunction & & & \\
$\quad$ Age (y) & & .042 & $1.05(1.00-1.09)$ \\
Genetic disorder & & .0012 & $9.46(2.43-36.78)$ \\
$\quad$ Renal dysfunction & & .0010 & $4.35(1.82-10.39)$ \\
$\quad$ Malperfusion & & .0015 & $3.81(1.67-8.70)$ \\
\hline$C I$, Confidence interval; $C A D$, coronary artery disease; $H C A$, hypothermic circulatory arrest; $T A R$, total arch replacement; $S C I$, spinal cord ischemia; $N A$, not applicable.
\end{tabular}

$C I$, Confidence interval; $C A D$, coronary artery disease; $H C A$, hypothermic circulatory arrest; TAR, total arch replacement; $S C I$, spinal cord ischemia; $N A$, not applicable. 
TABLE 4. Fate of the false lumen and secondary procedures among survivors* who underwent computed tomography after intervention

\begin{tabular}{|c|c|c|c|c|}
\hline & Overall & Stent & Standard treatment & $P$ value \\
\hline CT findings & $(\mathrm{n}=121)$ & $(\mathrm{n}=52)$ & $(n=69)$ & \\
\hline DTA false-lumen thrombosis & $43(35.5)$ & $23(44.2)$ & $20(29.0)$ & .083 \\
\hline Stent-area false-lumen thrombosis & $37(30.6)$ & $37(71.2)$ & NA & NA \\
\hline DTA complete thrombosis/remodeling & $53(43.8)$ & $33(63.5)$ & $20(29.0)$ & .0002 \\
\hline TAA complete thrombosis/remodeling & $27(22.3)$ & $15(28.9)$ & $12(17.4)$ & .13 \\
\hline TAA patent (includes partial thrombosis) & $88(72.7)$ & $36(69.2)$ & $52(75.4)$ & .45 \\
\hline Secondary procedures & $(\mathrm{n}=148)$ & $(\mathrm{n}=54)$ & $(\mathrm{n}=94)$ & \\
\hline DTA and TAA repairs $\dagger$ & $20(13.5)$ & $5(9.3)$ & $15(16.0)$ & .25 \\
\hline Endovascular procedures & $7(4.7)$ & $3(5.6)$ & $4(4.3)$ & .72 \\
\hline Open repairs & $16(10.8)$ & $4(7.4)$ & $12(12.8)$ & .31 \\
\hline
\end{tabular}

$C T$, Computed tomography; DTA, descending thoracic aorta; $N A$, not available; TAA, thoracoabdominal aorta. *Survival defined as no death before 30 days or before hospital discharge. $†$ Three patients had both open and endovascular follow-up procedures.

immediate survival at the end of the surgical procedure. The secondary goal is to avoid reoperation on the remaining dissected proximal, descending thoracic, and thoracoabdominal aortas. Although our subsequent arch procedures in patients with prior type I aortic dissection have had acceptable results, ${ }^{17}$ additional operations in the arch and the thoracoabdominal aorta can increase the rates of morbidity and mortality in these patients. The exponentially increasing use of stent grafts for almost all pathologies of the descending thoracic aorta, together with the promising results of the INSTEAD XL trial, ${ }^{18}$ have incited a new trend of antegrade or retrograde stent placement in the descending thoracic aorta simultaneously with the replacement of the proximal aorta during the repair of an acute type I aortic dissection. ${ }^{11-13}$

In this study, we examined both short- and mid-term clinical and imaging data from 2 groups of patients treated for acute type I aortic dissection. One group of patients underwent the standard repair (emergency replacement of the

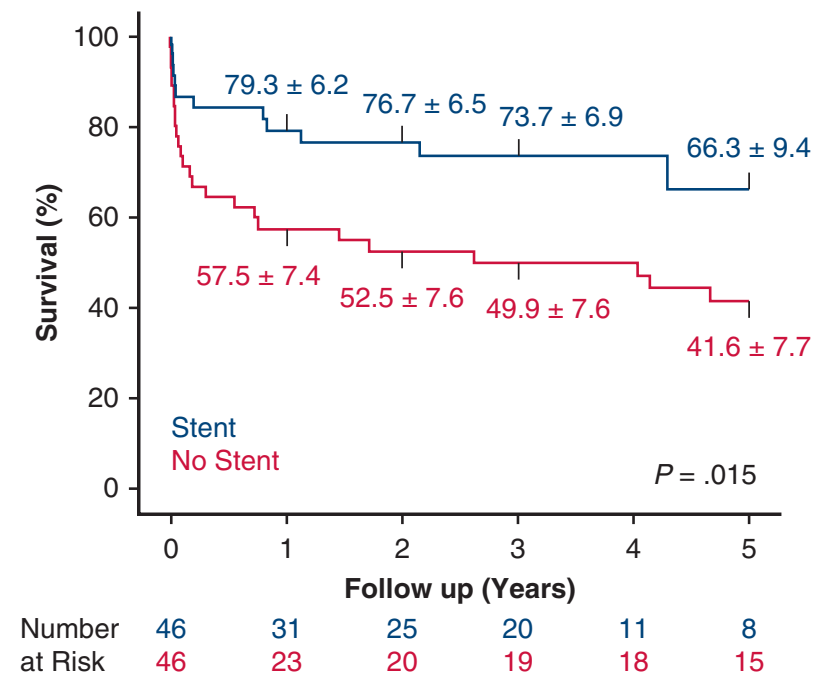

FIGURE 3. Kaplan-Meier survival curves for the matched stented and standard treatment groups. proximal aorta, with or without total arch replacement), and the other group additionally underwent simultaneous placement of a stent graft in the proximal and middescending thoracic aorta.

Operative mortality was more frequent in the standard repair group. This corresponds with the finding in our multivariable analysis that stent placement appeared to be protective against operative mortality. One explanation could be that preoperative malperfusion, which is a significant risk factor for adverse events as shown in this study and others, ${ }^{19,20}$ is often alleviated by stenting. Our earlier results ${ }^{11}$ suggest that antegrade stent delivery may help resolve malperfusion; however, this finding was not supported in the current study. Nevertheless, in more than $70 \%$ of patients who presented with preoperative malperfusion, the malperfusion was resolved in both groups after the proximal repair, regardless of whether the descending thoracic aorta was stented. Future collaborative studies with more patients could answer this question.

The matched and unmatched patients had similar persistent stroke rates, which resembled rates described by others. ${ }^{13,21}$ This finding supports the argument that the longer circulatory arrest time that may be associated with antegrade stent delivery is safe and does not contribute to perioperative stroke. The mean antegrade cerebral perfusion and circulatory arrest times were longer in the stented group for the matched and unmatched patients, which agrees with previous findings. ${ }^{13}$ In our previous study, ${ }^{11}$ we found no such difference; the most likely explanation is our recent addition of a circumferential row of 3-0 Prolene sutures to anchor the graft in the distal arch and the proximal descending thoracic aorta, which we did not perform early in the series.

The main concern regarding placing a stent in the descending thoracic aorta is the possibility of spinal cord injury due to coverage of intercostal arteries. Indeed, the risk of spinal cord injury appears to be higher in stented patients than in patients who undergo standard repair. ${ }^{22}$ However, selecting a distal landing zone above T10-T12 for 
some patients ${ }^{22}$ and above the T7 level for others ${ }^{23}$ appears to diminish this risk. In our study, permanent spinal cord ischemia rates were similar in both groups, although stenting was associated with nonsignificantly higher rates of transient paraplegia or paraparesis among the matched patients. The overall numbers are too small to draw any definitive conclusions; nonetheless, our results suggest that judicious caution is needed. Specifically, we try to cover only the upper part of the descending thoracic aorta, with the intention of performing further interventions during the subacute or chronic phase to treat the remaining descending or thoracoabdominal aorta. Spinal cord ischemia can also result from a primary central repair because of false lumen thrombosis and remodeling, which itself can thrombose some of the intercostals. We had no such incidents in this series.

We more frequently encountered remodeling of the descending thoracic aorta in the stent group than in the standard repair group. In addition, we found that a higher percentage of patients in the standard repair group underwent subsequent operations downstream of the thoracic aorta. The majority of these operations were open repairs in the standard group, whereas subsequent procedures were more often endovascular in the stent group. None of these differences were significant. It is difficult to speculate what the results might be if the stent were custom designed to cover the entire arch.

In patients with acute type I aortic dissection, antegrade stent delivery in the descending thoracic aorta can mitigate dilation by inducing false-lumen thrombosis and remodeling of the thoracoabdominal aorta. However, this remodeling did not translate into significantly fewer subsequent procedures in the thoracoabdominal aorta, which confirms that if complete thrombosis does not occur, the false lumen remains pressurized and can still dilate.

Others have shown that patency of the false lumen is associated with late mortality ${ }^{24}$ and that partial thrombosis is associated with worse long-term prognosis than complete thrombosis or complete patency. ${ }^{25}$ In our study, we noticed that late mortality was not associated with the status of patency of the false lumen, even though a higher rate of late mortality was seen in the partial thrombosis group. We did notice in the matched cohort that survival was significantly better in the stented group.

\section{Study Limitations}

Limitations of our study include its retrospective design and the sample size, which is large for a single institution but still small for statistical purposes. In addition, imaging data are longitudinal, but in this study, we had access to only the latest imaging data for each patient and not to all follow-up imaging data. Nevertheless, reports such as this one, examining carefully the new trends in the treatment of acute type I aortic dissection, are important. Mid-term results and imaging data are useful as we try to determine the ideal extent of the initial repair in patients with acute type I aortic dissection.

\section{CONCLUSIONS}

Our data suggest that more extensive repair that includes antegrade stent delivery may contribute to lower mortality rates. The association with spinal cord ischemia is unclear, because the overall numbers are too small to draw any definitive conclusions. Judicious caution is needed to avoid extensive coverage of the descending thoracic aorta during primary repair. Promising remodeling in the descending thoracic aorta and the thoracoabdominal aorta was seen with the hybrid stent technique, which was also associated with fewer subsequent downstream procedures, although the difference was not significant and the stented patients' survival was better.

\section{Conflict of Interest Statement}

J.S.C. participates in clinical research trials conducted by Edwards Lifesciences and Bolton Medical; consults for, receives royalties and a departmental educational grant from, and participates in clinical trials for Vascutek Terumo; and consults and participates in clinical trials for Medtronic, Inc, and WL Gore \& Associates. O.P. consults for Medtronic, Inc, and WL Gore \& Associates and has received travel expenses from Cook Medical, Inc. S.A.L. has served as a consultant for Terumo Aortic; has served as an Advisory Panel Member for Biom'up; serves as a principal investigator for clinical studies sponsored by Terumo Aortic and CytoSorbants; and serves as a co-investigator for clinical studies sponsored by WL Gore \& Associates. All other authors have nothing to disclose with regard to commercial support.

Stephen N. Palmer, PhD, ELS, contributed to the editing of the manuscript. Dr LeMaire's work is supported in part by the Jimmy and Roberta Howell Professorship in Cardiovascular Surgery at Baylor College of Medicine.

\section{References}

1. Berretta P, Patel HJ, Gleason TG, Sundt TM, Myrmel T, Desai N, et al. IRAD experience on surgical type A acute dissection patients: results and predictors of mortality. Ann Cardiothorac Surg. 2016;5:346-51.

2. Conzelmann LO, Weigang E, Mehlhorn U, Abugameh A, Hoffmann I, Blettner M, et al. Mortality in patients with acute aortic dissection type A: analysis of pre- and intraoperative risk factors from the German registry for acute aortic dissection type A (GERAADA). Eur J Cardiothorac Surg. 2016;49: e44-52.

3. Fusco DS, Shaw RK, Tranquilli M, Kopf GS, Elefteriades JA. Femoral cannulation is safe for type A dissection repair. Ann Thorac Surg. 2004;78:1285-9.

4. Keeling WB, Leshnower BG, Hunting JC, Binongo J, Chen EP. Hypothermia and selective antegrade cerebral perfusion is safe for arch repair in type A dissection. Ann Thorac Surg. 2017;104:767-72.

5. Pape LA, Awais M, Woznicki EM, Suzuki T, Trimarchi S, Evangelista A, et al. Presentation, diagnosis, and outcomes of acute aortic dissection: 17-year trends from the international registry of acute aortic dissection. J Am Coll Cardiol. 2015;66:350-8. 
6. Preventza O, Coselli JS. Differential aspects of ascending thoracic aortic dissection and its treatment: the North American experience. Ann Cardiothorac Surg. 2016;5:352-9.

7. Preventza O, Simpson KH, Cooley DA, Cornwell L, Bakaeen FG, Omer S, et al. Unilateral versus bilateral cerebral perfusion for acute type A aortic dissection. Ann Thorac Surg. 2015:99:80-7.

8. Rice RD, Sandhu HK, Leake SS, Afifi RO, Azizzadeh A, Charlton-Ouw KM, et al. Is total arch replacement associated with worse outcomes during repair of acute type A aortic dissection? Ann Thorac Surg. 2015;100:2159-66.

9. Rylski B, Milewski RK, Bavaria JE, Vallabhajosyula P, Moser W, Szeto WY, et al. Long-term results of aggressive hemiarch replacement in 534 patients with type A aortic dissection. J Thorac Cardiovasc Surg. 2014;148:2981-5.

10. Omura A, Miyahara S, Yamanaka K, Sakamoto T, Matsumori M, Okada K, et al. Early and late outcomes of repaired acute DeBakey type I aortic dissection after graft replacement. J Thorac Cardiovasc Surg. 2016;151:341-8.

11. Preventza O, Cervera R, Cooley DA, Bakaeen FG, Mohamed AS, Cheong BY, et al. Acute type I aortic dissection: traditional versus hybrid repair with antegrade stent delivery to the descending thoracic aorta. J Thorac Cardiovasc Surg. 2014;148:119-25.

12. Roselli EE, Rafael A, Soltesz EG, Canale L, Lytle BW. Simplified frozen elephant trunk repair for acute DeBakey type I dissection. J Thorac Cardiovasc Surg. 2013;145:S197-201.

13. Vallabhajosyula P, Szeto WY, Pulsipher A, Desai N, Menon R, Moeller P, et al. Antegrade thoracic stent grafting during repair of acute DeBakey type I dissection promotes distal aortic remodeling and reduces late open distal reoperation rate. J Thorac Cardiovasc Surg. 2014;147:942-8.

14. Roselli EE, Idrees JJ, Bakaeen FG, Tong MZ, Soltesz EG, Mick S, et al. Evolution of simplified frozen elephant trunk repair for acute DeBakey type I dissection: midterm outcomes. Ann Thorac Surg. 2018;105:749-55.

15. Preventza O, Price MD, Spiliotopoulos K, Amarasekara HS, Cornwell LD, Omer S, et al. In elective arch surgery with circulatory arrest, does the arterial cannulation site really matter? A propensity score analysis of right axillary and innominate artery cannulation. J Thorac Cardiovasc Surg. 2018;155: 1953-19560.e4.

16. Smith HN, Boodhwani M, Ouzounian M, Saczkowski R, Gregory AJ, Herget EJ, et al. Classification and outcomes of extended arch repair for acute Type A aortic dissection: a systematic review and meta-analysis. Interact Cardiovasc Thorac Surg. 2017;24:450-9.

17. Preventza O, Price MD, Simpson KH, Cooley DA, Pocock E, de la Cruz KI, et al Hemiarch and total arch surgery in patients with previous repair of acute type aortic dissection. Ann Thorac Surg. 2015;100:833-8.

18. Nienaber CA, Kische S, Rousseau H, Eggebrecht H, Rehders TC, Kundt G, et al. Endovascular repair of type B aortic dissection: long-term results of the randomized investigation of stent grafts in aortic dissection trial. Circ Cardiovasc Interv. 2013;6:407-16.

19. Czerny M, Schoenhoff F, Etz C, Englberger L, Khaladj N, Zierer A, et al The impact of pre-operative malperfusion on outcome in acute type A aortic dissection: results from the GERAADA registry. J Am Coll Cardiol. 2015;65 2628-35.

20. Lawton JS, Moon MR, Liu J, Koerner DJ, Kulshrestha K, Damiano RJ Jr, et al. The profound impact of combined severe acidosis and malperfusion on operative mortality in the surgical treatment of type A aortic dissection. J Thorac Cardiovasc Surg. 2018;155:897-904

21. Di Eusanio M, Castrovinci S, Tian DH, Folesani G, Cefarelli M, Pantaleo A, et al Antegrade stenting of the descending thoracic aorta during DeBakey type 1 acute aortic dissection repair. Eur J Cardiothorac Surg. 2014;45:967-75.

22. Hoffman A, Damberg AL, Schalte G, Mahnken AH, Raweh A, Autschbach R Thoracic stent graft sizing for frozen elephant trunk repair in acute type A dissection. J Thorac Cardiovasc Surg. 2013;145:964-9.

23. Katayama A, Uchida N, Katayama K, Arakawa M, Sueda T. The frozen elephan trunk technique for acute type A aortic dissection: results from 15 years of experience. Eur J Cardiothorac Surg. 2015;47:355-60.

24. Halstead JC, Meier M, Etz C, Spielvogel D, Bodian C, Wurm M, et al. The fate of the distal aorta after repair of acute type A aortic dissection. J Thorac Cardiovasc Surg. 2007;133:127-35.

25. Song SW, Chang BC, Cho BK, Yi G, Youn YN, Lee S, et al. Effects of partia thrombosis on distal aorta after repair of acute DeBakey type I aortic dissection. J Thorac Cardiovasc Surg. 2010;139:841-7.e1.

Key Words: aortic dissection, aortic arch surgery, stenting, survival, acute type I aortic dissection 